\title{
TEMPORAL RELATIONSHIP BETWEEN CHANGES IN OXYTOCIN AND PROSTAGLANDIN F LEVELS IN RESPONSE TO VAGINAL DISTENSION IN THE PREGNANT AND PUERPERAL EWE
}

\author{
A. P. F. FLINT, MARY L. FORSLING,* M. D. MITCHELL \\ AND A. C. TURNBULL \\ Nuffield Department of Obstetrics and Gynaecology, \\ John Radcliffe Hospital, Headington, Oxford OX3 9DU, and \\ *Department of Physiology, Middlesex Hospital Medical School, \\ Cleveland Street, London W1P $7 P \mathcal{N}$
}

(Received 20th November 1974)

Summary. To investigate the rôle of oxytocin in the increase in utero-ovarian venous prostaglandin F (PGF) level caused by vaginal distension, jugular venous oxytocin and utero-ovarian venous PGF were measured simultaneously in one sheep in late pregnancy and in one sheep shortly before parturition. Vaginal distension raised oxytocin and PGF levels in both animals and oxytocin levels increased before those of PGF. These findings support the suggestion that the elevated PGF levels resulting from vaginal distension are caused by the reflex secretion of oxytocin.

Vaginal distension in the late pregnant ewe causes an immediate rise in uteroovarian venous prostaglandin F (PGF) level (Flint, Anderson, Patten \& Turnbull, 1974). This effect can be copied by administration of oxytocin (Mitchell, Flint \& Turnbull, 1975). If the effect of vaginal distension on PGF is mediated by the reflex release of oxytocin (Ferguson, 1941; Debackere, Peeters \& Tuyttens, 1961; Roberts \& Share, 1968), it should be possible to demonstrate a rise in oxytocin level preceding the rise in PGF. This report describes experiments designed to test this possibility.

Utero-ovarian and jugular venous catheters were established in two ewes towards the end of pregnancy. In both animals, labour was of spontaneous onset and live lambs were born. Vaginal distension was performed by inserting the gloved hand in the vagina for 2 to $4 \mathrm{~min}$ with the animals standing in a cage. Blood samples were collected into ice-cold heparinized plastic tubes and stored in ice until separation of the plasma within $30 \mathrm{~min}$. Oxytocin was measured in jugular venous plasma by radioimmunoassay (Chard, Boyd, Forsling, McNeilly \& Landon, 1970) of extracts prepared using porous glass beads (Ratcliffe \& Edwards, 1971). The PGF was measured by radioimmunoassay in uteroovarian venous plasma after extraction with diethyl ether and chromatography on columns of silicic acid (Flint et al., 1974; Mitchell et al., 1975). 
In the animal investigated in late pregnancy (Text-fig. 1), vaginal distension was performed 5 days before parturition (3 days after catheterization). Two control samples of jugular venous plasma contained $<0.88$ and $1.3 \mu \mathrm{U}$ oxytocin/ $\mathrm{ml}$. In response to vaginal distension, the oxytocin level increased to $15 \mu \mathrm{U} / \mathrm{ml}$ within $1 \mathrm{~min}$. The oxytocin level was also high $(9.5 \mu \mathrm{U} / \mathrm{ml})$ in a second sample obtained during vaginal distension; thereafter the level dropped, approaching baseline values $(3.0 \mu \mathrm{U} / \mathrm{ml}) 13$ min after removing the hand from the vagina. Utero-ovarian venous PGF levels also increased in response to vaginal distension, reaching a maximum of $7.4 \mathrm{ng} / \mathrm{ml}$ in a sample obtained $1 \mathrm{~min}$ after distension ceased. One sample taken during vaginal distension did not contain high PGF levels; this was obtained I min after the jugular venous sample in which oxytocin was first found to be elevated. Thus, the oxytocin level rose between 1 and 4 min before that of PGF.

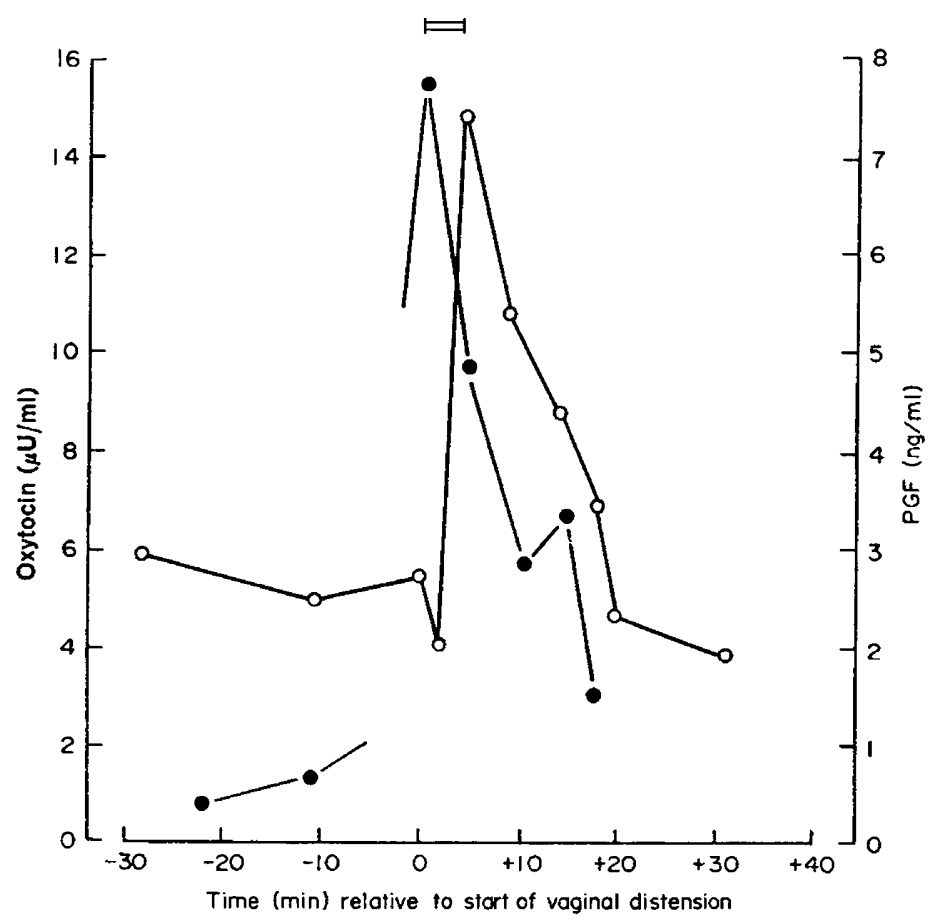

TexT-Fig. 1. Effect of vaginal distension (for $4 \mathrm{~min}$, as indicated by the horizontal bar) on jugular venous oxytocin $(\bullet)$ and utero-ovarian venous PGF $(0)$ in one ewe 5 days before the birth of live twins on Day 147 post coitum.

Oxytocin and PGF levels responded to vaginal distension in a similar way $18 \mathrm{hr}$ post partum (Text-fig. 2). In this animal, catheters were inserted 4 days before parturition. Although gestational age was not determined accurately, the lamb was mature when born, and survived without treatment. Basal oxytocin levels were 1.8 to $3.6 \mu \mathrm{U} / \mathrm{ml}$; the highest level observed (during vaginal distension) was $53.3 \mu \mathrm{U} / \mathrm{ml}$. Levels dropped after vaginal distension, but did not return immediately to baseline values. The PGF was not elevated during vaginal distension, but a sample obtained $1 \mathrm{~min}$ after removing the hand from 
the vagina contained high levels $(169 \mathrm{ng} / \mathrm{ml})$. Thereafter the PGF level increased, reaching a maximum $(298 \mathrm{ng} / \mathrm{ml}) 3 \mathrm{~min}$ after ending distension. In this instance, therefore, an elevated oxytocin level was observed $2 \mathrm{~min}$ before the first elevated PGF level.

These findings not only establish that oxytocin, as well as PGF, rises in response to vaginal distension in late pregnancy and the puerperium, but also that the rise in oxytocin precedes that of PGF. This clearly supports the hypothesis that vaginal distension raised PGF levels by way of a reflex release of oxytocin.

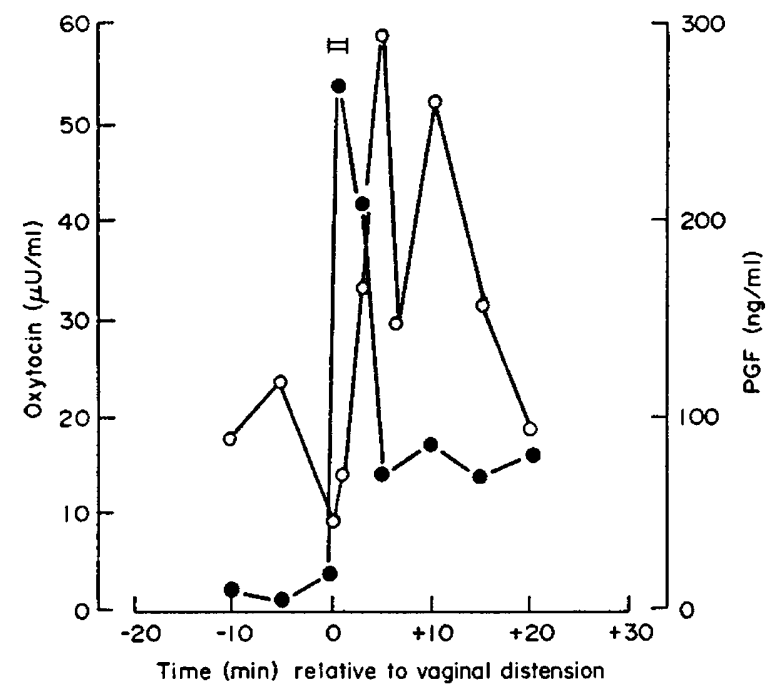

TExT-Fra. 2. Effect of vaginal distension (for $2 \mathrm{~min}$, as indicated by the horizontal bar) on
jugular venous oxytocin (๑) and utero-ovarian venous PGF (O) in one ewe $18 \mathrm{hr}$ after the birth of live twins.

Although it has been shown before that vaginal distension raises circulating oxytocin levels in lactating ewes (Roberts \& Share, 1968), this has not previously been demonstrated in pregnancy. In fact, Roberts \& Share (1968) observed a decrease in jugular venous oxytocin after vaginal distension on Days 75 to 115 of gestation. The previous inability to detect an increase may be due to an inherent lack of specificity in earlier assays. Basal levels of oxytocin reported by Roberts \& Share (1968) support this: their levels are approximately tenfold those of Alexander, Britton, Forsling, Nixon \& Ratcliffe (1971) and those reported here in late pregnancy. Alternatively, as Roberts \& Share speculated, it may reflect some change in response between 75 and 115 days (when Roberts \& Share demonstrated a negative effect of vaginal distension) and 142 days (when we have observed a stimulatory effect). Roberts \& Share (1969) reported the inhibition of oxytocin release by progesterone and stimulation by oestrogen. The difference in response is unlikely, however, to be due to a change in steroid hormonal milieu in the present investigation since the animal in late pregnancy was studied before the drop in progesterone and the rise in oestrogen levels which occur at term (Bassett, Oxborrow, Smith \& Thorburn, 1969; Fylling, 1970; Challis, 1971).

Reflex secretion of oxytocin after vaginal distension (Ferguson, 1941) is

L 
likely to be most important in parturition, when the fetal snout and fore-limbs distend the vagina in the second stage of labour; most recent evidence indicates that oxytocin is largely released during the expulsive phase (Chard, 1972). In view of the close relationship between oxytocin and PGF suggested by the present work, it appears likely that the high utero-ovarian venous PGF levels observed in second-stage labour (Currie, Wong, Cox \& Thorburn, 1973; Flint et al., 1974) may be due to oxytocin secretion (Fitzpatrick \& Walmsley, 1965). A reflex release of oxytocin and PGF stimulated by suckling may facilitate expulsion of the placenta immediately after parturition: Allen, Chard \& Forsling (1973) have shown in the horse that the delivery of the placenta is accompanied by the release of oxytocin.

Thanks are due to Professor G. S. Dawes, for allowing us to use the animal facilities at the Nuffield Institute for Medical Research, University of Oxford. This work was supported by Medical Research Council Grant G 971809C, and one of us (M.D.M.) holds a Medical Research Council Studentship.

\section{REFERENCES}

Alexander, D. P., Britton, H. G., Forsling, M. L., Nixon, D. A. \& Ratcliffe, J. G. (1971) The concentration of adrenocorticotrophin, vasopressin and oxytocin in the foetal and maternal plasma of the sheep in the latter half of gestation. F. Endocr. 49, 179-180.

Alren, W. E., Chard, T. \& Forsling, M. L. (1973) Peripheral plasma levels of oxytocin and vasopressin in the mare during parturition. $\mathcal{F}$. Endocr. 57, 173-176.

Bassett, J. M., Oxborrow, T. J., Smith, I. D. \& Thorburn, G. D. (1969) The concentration of progesterone in the peripheral plasma of the pregnant ewe. 7. Endocr. 45, 449-457.

Challis, J. R. G. (1971) Sharp increase in free circulating oestrogens immediately before parturition in sheep. Nature, Lond. 229, 208.

Chard, T. (1972) The posterior pituitary in human and animal parturition. F. Reprod. Fert., Suppl. $16,121-138$.

Ghard, T., Boyd, N. R. H., Forsling, M. L., McNeilly, A. S. \& Landon, J. (1970) The development of a radioimmunoassay for oxytocin; the extraction of oxytocin from plasma and its measurement during parturition in human and goat blood. F. Endocr. 48, 223-234.

Currie, W. B., Wong, M. S. F., Cox, R. I. \& Thorburn, G. D. (1973) Spontaneous or dexamethasoneinduced parturition in the sheep and goat: changes in plasma concentrations of maternal prostaglandin F and foetal oestrogen sulphate. Mem. Soc. Endocr. 20, 95-118.

Debackere, M., Peeters, G. \& Tuyttens, N. (1961) Reflex release of an oxytocic hormone by stimulation of genital organs in male and female sheep studied by a cross-circulation technique. 7. Endocr. 22, 321-334.

Ferguson, J. K. W. (1941) A study of the motility of the intact uterus at term. Surgery, Gynec. Obstet. 73, 359-366.

FitzPatrick, R. J. \& WALMSLEY, C. F. (1965) The release of oxytocin during parturition. In Advances in Oxytocin Research, pp. 57-71. Ed. J. H. M. Pinkerton. Pergamon Press, London.

Flint, A. P. F., Anderson, A. B. M., Patten, P. T. \& Turnbull, A. C. (1974) Control of utero-ovarian venous prostaglandin $\mathrm{F}$ during labour in the sheep: acute effects of vaginal and cervical stimula. tion. F. Endocr. 63, 67-87.

Fyluing, P. (1970) The effect of pregnancy, ovariectomy and parturition on plasma progesterone level in sheep. Acta endocr., Copenh. 65, 273-283.

Mitchell, M. D., Flint, A. P. F. \& TURnbull, A. C. (1975) Stimulation by oxytocin of prostaglandin F levels in uterine venous effluent in pregnant and puerperal sheep. Prostaglandins (in press).

Ratcliffe, J. G. \& Ebwards, C. R. W. (1971) The extraction of adrenocorticotrophin an darginine vasopressin from human plasma by porous glass. In Radioimmunoassay Methods, pp. 502-512. Eds. K. E. Kirkham and W. M. Hunter. Livingstone, Edinburgh.

Roberts, J. S. \& Share, L. (1968) Oxytocin in plasma of pregnant, lactating and cycling ewes during vaginal stimulation. Endocrinology, 83, 272-278.

Roserts, J. S. \& Share, L. (1969) Effects of progesterone and estrogen in blood levels of oxytocin during vaginal distension. Endocrinology, 84, 1076-1081. 